\title{
The OnWind Modelica Library for Offshore Wind Turbines - Implementation and first results
}

\author{
M. Strobel F. Vorpahl C. Hillmann $\quad$ X. Gu A. Zuga U. Wihlfahrt \\ Fraunhofer Institute for Wind Energy and Energy System Technology (IWES) \\ Michael.Strobel@iwes.fraunhofer.de
}

\begin{abstract}
At Fraunhofer IWES a Modelica Library including all major components needed for load calculations of current offshore wind turbines is developed. The library additionally includes models for external conditions, like wind, soil and waves, and their respective influence on the structures. The library constitutes a large effort in the creation of a highly coupled multiphysics model with Modelica for an industrial project. The results obtained with this library are compared to the results from the IEA Wind Task 23 project OC $3^{1}$ (Offshore code comparison collaboration). The OC3 project is an international effort to define a set of loadcases and a reference wind turbine that are used to verify simulation systems on a code-to-code basis. In this paper the status and the implemented theories of the individual models at IWES are explained and verification results are presented and discussed.
\end{abstract}

Keywords: offshore wind turbine simulation; aerodynamics; hydrodynamics; OC3 project; fully coupled simulation

\section{Introduction}

The use of wind energy as a renewable and comparably cost effective energy source has grown rapidly over the past decades. While today the majority of the turbines are mounted onshore, we are now facing a rapid development offshore as well.

This paper starts with an introduction to wind turbine simulation in general before describing the components of the OnWind library. In the last section the simulation results of this library are verified in comparison to results obtained in the OC3 project.

\footnotetext{
${ }^{1}$ www.ieawind.org/
}

\section{Wind turbine system simulation}

Wind turbines are designed and analyzed using simulation tools (i.e. design codes) capable of predicting the coupled dynamic loads and responses of the system. Land-based wind turbine analysis relies on the use of aero-servo-elastic codes, which incorporate wind-inflow, aerodynamic (aero), control system (servo) and structural-dynamic (elastic) models in the time domain in a coupled simulation environment. In recent years, some of these codes have been expanded to include the additional dynamics pertinent to offshore installations, including the incident waves, sea current, hydrodynamics and foundation dynamics of the support structure.

The design of wind turbines usually consists of a two step approach, starting with a fully coupled time domain simulation as - described above - which generates the loads for the following detailed design of all components. The certification rules for offshore wind turbines, like the "Design requirements for offshore wind turbines" issued by the International Electrotechnical Commission [7], define a large set of load cases that have to be considered in the design phase.

\section{Components of the library}

Due to the object-oriented structure of Modelica, the different components needed for the simulation of the turbine can be implemented independently. In this chapter the different components are described in brief.

The structure of the OnWind library is shown in Figure 2 .

\subsection{Wind}

In the OnWind library, wind models for simple cases including exponential wind shear are available. For 


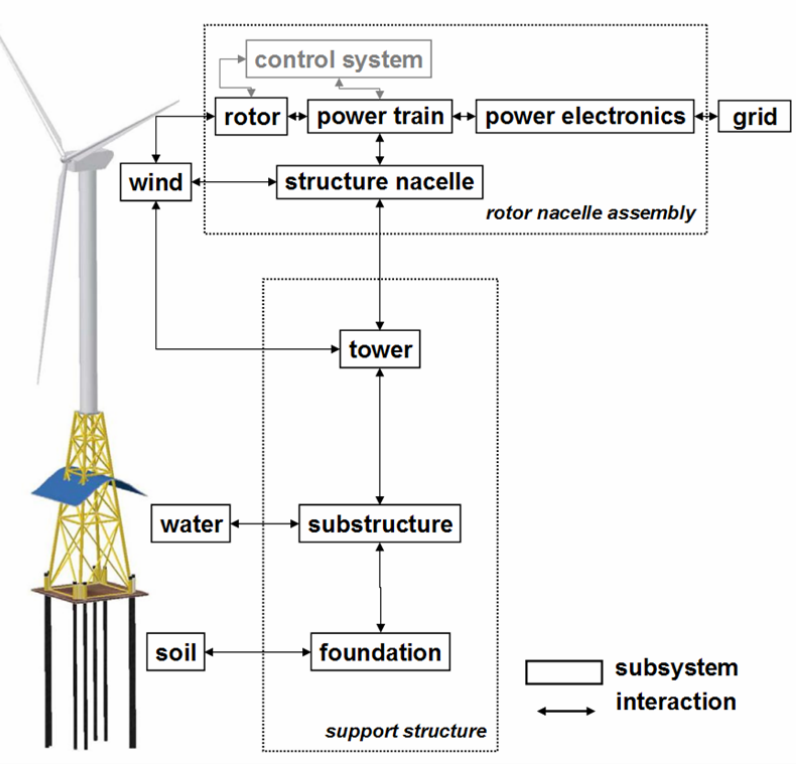

Figure 1: Major components of an offshore wind turbine

certification purposes even more complex wind models are needed which are currently under development. As these stochastic models for turbulent wind definition (Kaimal [11] and Von Karman spectra [12]) are available as open source free-to-use FORTRAN software from the National Renewable Energy Laboratory of the US (TurbSim, [8]), this software is currently used for the calculations. The interface between TurbSim and the wind turbine model is part of the OnWind library. For the integration of these external wind files an optimal tradeoff between memory consumption and calculation performance is achieved.

\subsection{Aerodynamics}

A basic standard for wind turbine simulation tools is the "Blade element momentum theory (BEM)", as described by [17], [4] and extended by [3], [6], which is used to calculate induced wind velocities and aerodynamic loads. This method is incorporated in the library including the blade tip losses, the hub losses [6] and corrections for the turbulence wake state [5]. Additionally the tower interference is accounted for in the aerodynamic model.

\subsection{Rotor blade structure}

For the modeling of the structure of the rotor blades there are currently two models available, a rigid model and a flexible one. The rigid model can be used for rough calculations and has significant advantages in

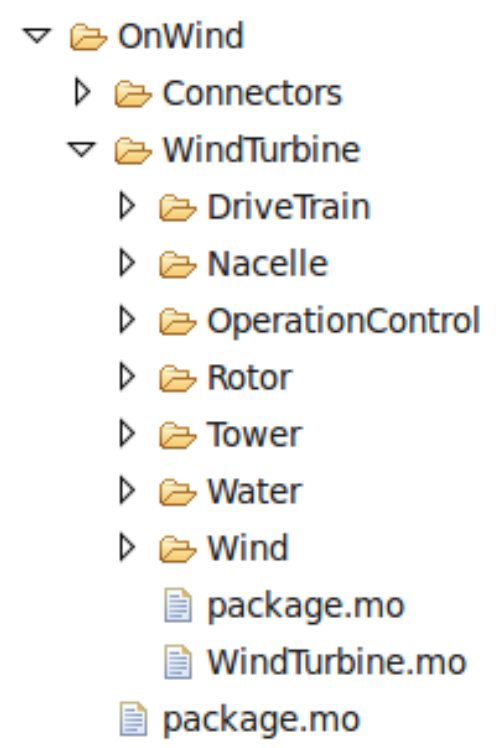

Figure 2: Structure of the OnWind library

terms of performance. For the flexible blades a finiteelement formulation based on Euler-Bernoulli beam theory is implemented. The structural analysis and the aerodynamic calculations are coupled in this model to simulate the flexible rotor.

\subsection{Hub and nacelle}

As in most software systems for fully-coupled wind turbine simulation the hub and the nacelle are modeled as rigid links contributing masses and inertias.

\subsection{Drive train and generator}

The drive train is incorporated in the library as a two mass torsional oscillator, contributing inertia, gearbox ratio, stiffness and damping. For more accurate and computational costly simulations of the drive train the DLR drive train library can be used, as it is compatible to the OnWind library.

As in most of the wind turbine simulation codes the generator is included with its mechanical characteristics, but more advanced models from the Modelica Standard Library or other libraries may be used.

\subsection{Control}

The control module of the OnWind library consist on the one hand of control sequences to handle different operating conditions and on the other hand of conventional methods to control different parts of the wind turbine. 
In the operation control package relevant inputs and outputs are processed to adjust corresponding operating states of the wind turbine. This is done by a simple decision algorithm but can also be realized using state charts with e.g. the MODELICA StateChart2 library [15]. To retrieve measured process signals and transferring controller output signals, the communication with sensors and actuators is accomplished by the signal bus concept of MODELICA as described by Martin Otter [14]. This eases the integration of already implemented or new signals into and out of the control modules. Before processing input signals in the control algorithms preprocessing functions like e.g. low pass filtering of generator speed is performed.

Control methods are implemented for blade pitching and controlling the generator torque. For aerodynamic power control a collective pitch control with PI-algorithm is used. To account for the non-linear behaviour of aerodynamic profiles a gain-scheduling algorithm is used like discussed in [9]. Limit conditions are also considered and other linear control structures like PID and Anti-Wind-Up may be used.

To accomplish generator variable-speed operation and energy capture maximization it is possible to set a characteristic generator torque vs. speed curve. The curve is the basis for setting the generator torque on different speeds by an suitable algorithm. For performance optimization also a Maximum-Power-PointTracking algorithm is implemented, which calculates the optimal speed for changing operating conditions.

\subsection{Tower and substructure}

For the tower and the substructure a finite element approach is used (Euler-Bernoulli beam elements). This allows for modeling of arbitrary support structures, like the jacket shown in Figure 3. Simple monopiles can be modeled with this approach as well.

For the calculation of the forces resulting from water waves and currents, Morison's formula [13] is incorporated in the substructure models.

\subsection{Soil and water}

Several currently available tools for wind turbine simulation model the soil rather simple with one $6 \times 6$ stiffness matrix or just as a clamped beam. In OnWind this is possible too, but the more advanced p-y-approach is incorporated as well. With this approach, also described by the American Petroleum Institute ([2]), the soil is modeled with nonlinear springs. Additionally
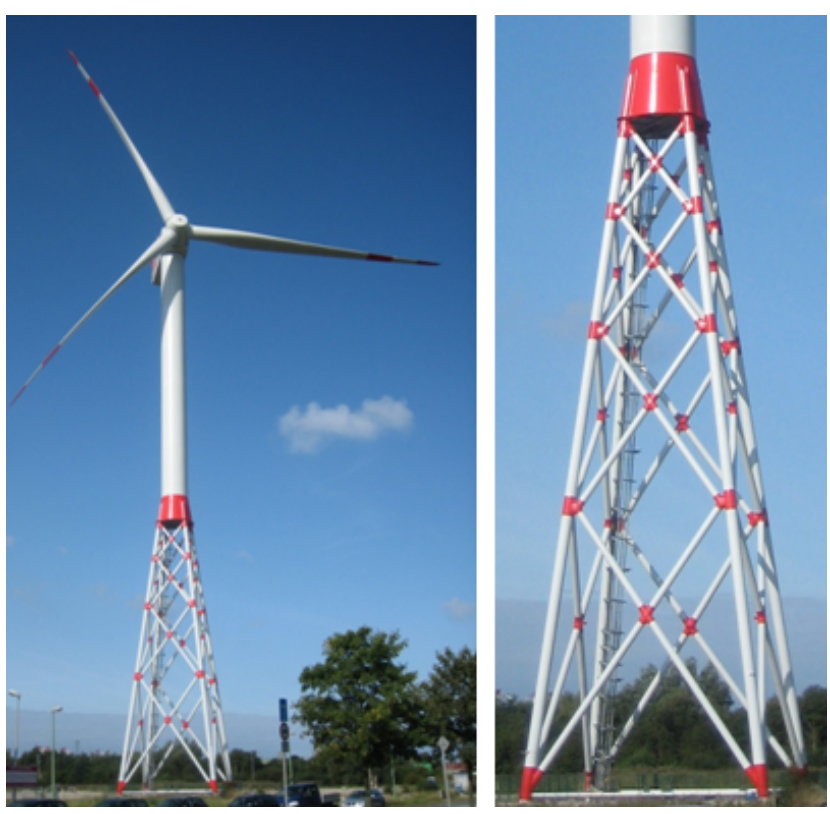

Figure 3: Turbine on jacket substructure extended by tubular tower (prototype erected onshore)

damping elements are available to describe the soil as realistic as possible.

Using the OnWind library single linear waves (Airy [1]) from different angles may be defined. Nonlinear waves based on a Stream Function theory are available as well as spectrum based linear irregular waves defined by means of JONSWAP spectra. Development and first verification of hydrodynamic features are described in [16].

\subsection{Connectors}

Most of the wind turbine components described earlier in this document use predefined connectors like the frame connector from the multibody library to connect adjacent components of the wind turbine. Therefore it is easily possible to integrate enhanced models for subcomponents using parts of the Modelica Standard Library. However some of the wind turbine components need special connectors to be able to model the interaction between each other.

Especially the connections between the components modeled with the finite-element approach (rotorblade structure, tower and substructure models) and the models describing the loads on these components (wind and wave models) needed to be developed.

For example the connection between the wind and the rotorblade is realized by two connectors connecting the wind model via the aerodynamics model to the rotorblade model like shown in Figure 4. For the con- 
nection between the wind model and the aerodynamics model a connector has been developed containing the actual position of the structure and the velocities of the wind. The forces calculated in the aerodynamics model are connected to the structure model via another connector containing the position of the structure and the forces applied on the structure. The same approach is used to describe the interaction between the water model and the models for the tower and the substructure.

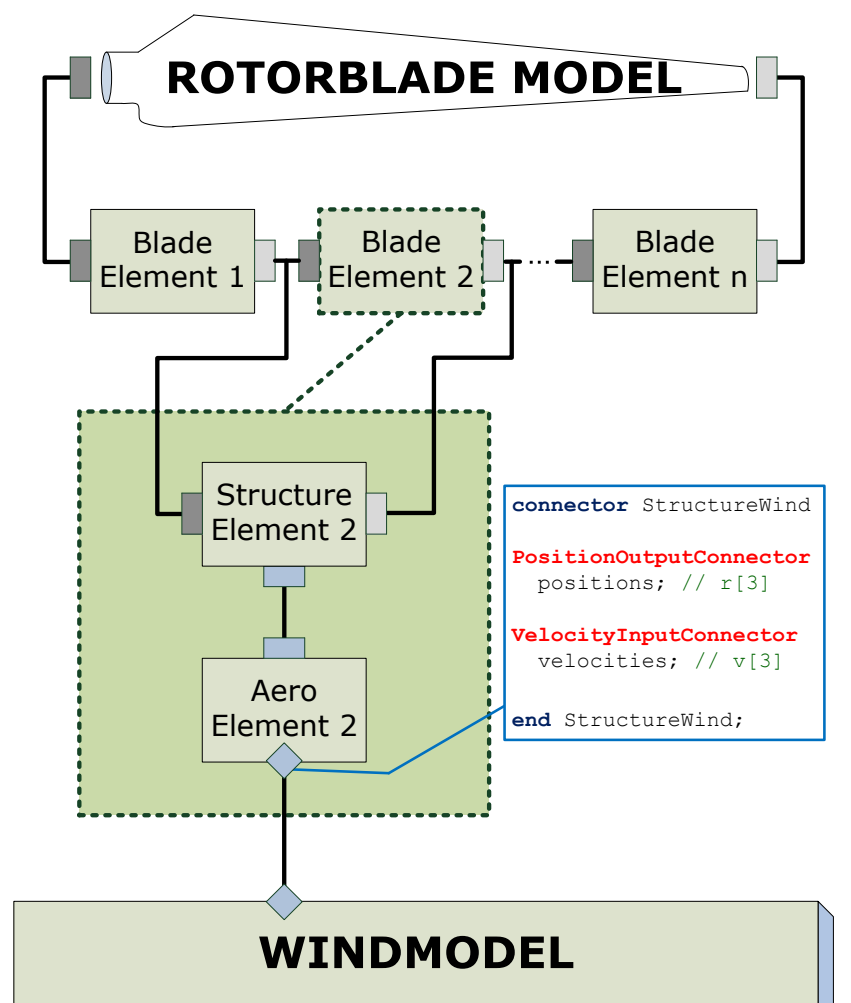
connector

\section{Aero load}

connector

Wind - structure connector
Modelica frame

Figure 4: Connector schema for rotorblade and wind

\section{Verification of the OnWind library}

In this chapter, the offshore wind turbine that is used in this benchmarking task and the OC 3 project - in which e.g load cases and support structures are defined - is briefly described. Furthermore, results calculated with OnWind are presented and interpreted in comparison to results from other tools.

\subsection{The NREL 5-MW baseline wind turbine}

The NREL 5-MW baseline wind turbine developed for code comparison purposes is a lifelike three-bladed variable speed 5-MW upwind turbine with collective pitch control. The model is based on available design information from turbine manufacturers with an emphasis on the REpower 5M machine. Detailed data is provided by research projects - with a focus on the Dutch Offshore Wind Energy Converter (DOWEC) project - where design data is not available due to confidentiality reasons. Special emphasis was set on combining the best available and the most representative data. The turbine definition includes aerodynamic and structural data as well as the definition of a basic control-system. For more details on the turbine cf. [9].

\subsection{The OC3 project}

The sophistication of the aero-hydro-servo-elastic codes (as described in section 2), and the limited data available with which to validate them, provided the incentive to set up an international code-to-code comparison project in order to validate these tools. This task was accomplished in the Offshore Code Comparison Collaboration (OC3) project, which operated under Subtask 2 of the International Energy Agency (IEA) Wind Task 23 [10].
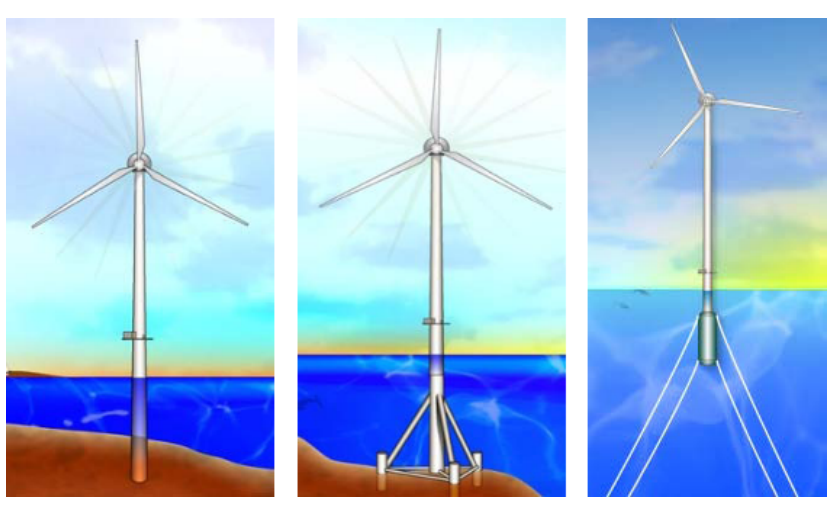

Figure 5: The support structures investigated in the OC3 project [10]

The general approach of the project is to (1) discuss modeling strategies, (2) develop a suite of benchmark models and simulations, (3) run the simulations and process the simulation results and (4) compare and discuss the results.

A large set of time series simulation results such as turbine operational characteristics, external conditions as well as load and displacement outputs were compared and interpreted. Load cases were defined and 
run with increasing complexity to be able to trace back differences in simulation results to the underlying error sources.

Within the project, the NREL 5-MW baseline wind turbine is modeled in combination with four different substructure types in four phases: The monopile implemented in Phase I is designed for a water depth of $20 \mathrm{~m}$ with its transition to the tower $10 \mathrm{~m}$ above the mean sea level (MSL). This structure is used for the validation in the following chapter.

\subsection{Results comparison}

The loadcases in Phase I of the OC3 project are designed in different stages, from rigid structure over a flexible onshore model to a flexible offshore turbine with additional hydrodynamic loads. In the following, exemplary time series results from the last stage of a fully coupled flexible offshore model with deterministic wind and wave conditions are presented. For the following comparison the results of three well known participants (GL Garrad Hassan, NREL, Ris $\varnothing$ DTU) of the OC3 project are taken into account ${ }^{2}$.

In Figure 6 and 7 the gear-box translated generator speed and the generated power of the turbine at a constant wind speed of $8 \mathrm{~m} / \mathrm{s}$ is shown.

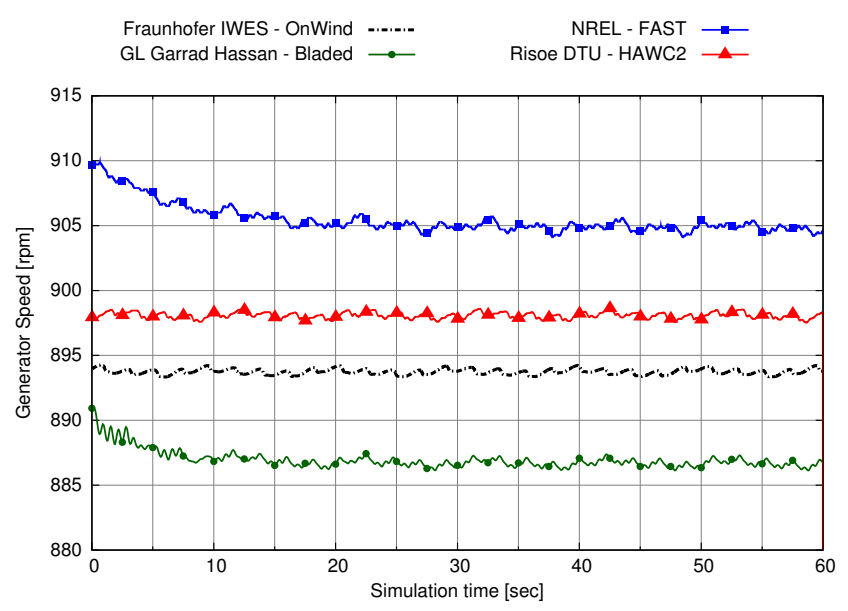

Figure 6: Time series of generator speed in [rpm]

The results of the OnWind library are located in a range of $2 \%$ difference for the absolute values which is due to different implementations of the aerodynamics model. The main reason for the oscillating behaviour is the influence of the tower shadow.

\footnotetext{
${ }^{2}$ http://www.ieawind.org/Annex_XXIII.html
}

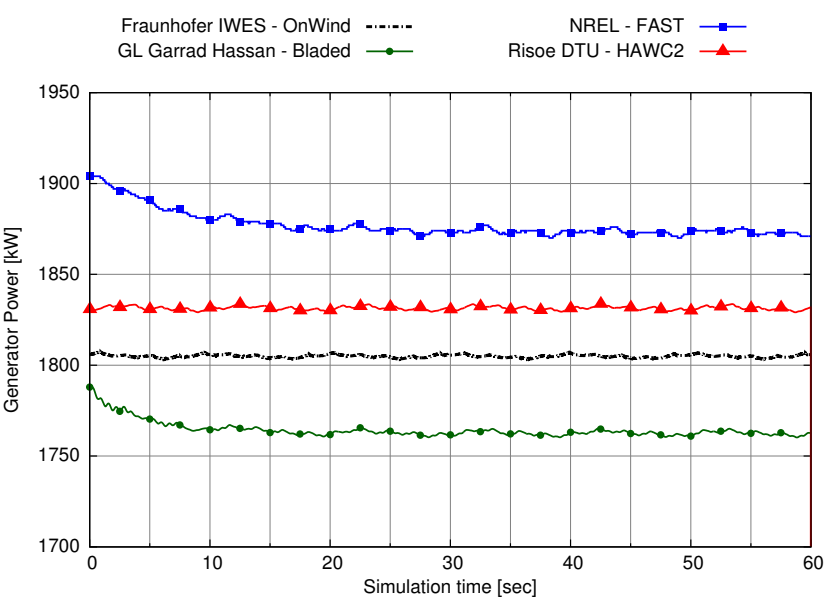

Figure 7: Time series of electrical generator power output in $[\mathrm{kW}]$

As we deal with a flexible structure, deflections of the blade tip are illustrated in the next diagrams. Both results, the out-of-plane (Figure 8) and the inplane (Figure 9) deflections are in good agreement. The smoother form of the deflection curves from OnWind is the result of not yet included extensions to the aerodynamical model like dynamic stall and correction for skewed inflow, which are currently in development.

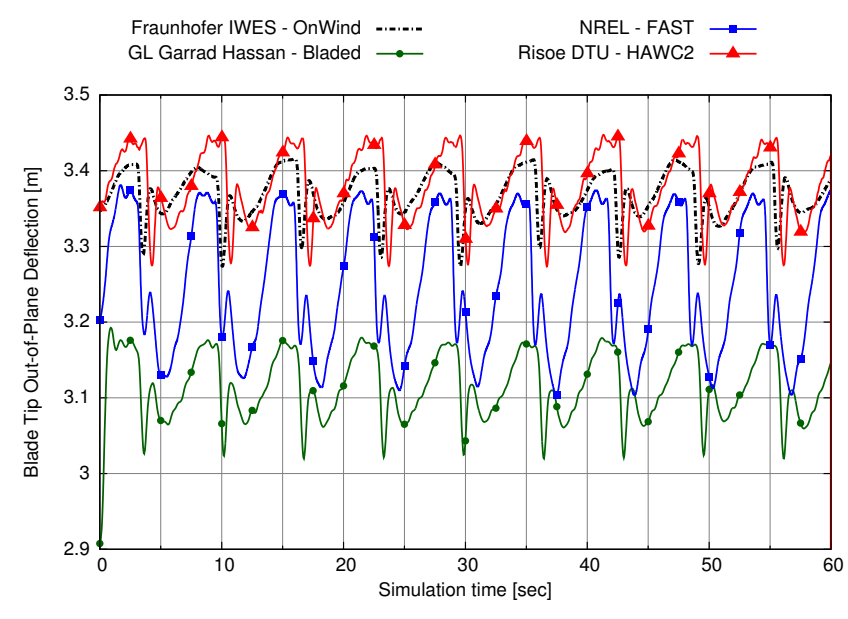

Figure 8: Time series of out-of-plane blade tip deflection in $[\mathrm{m}]$

As mentioned above, the investigated loadcase encloses hydrodynamic loads from deterministic wave conditions with a regular wave of $6 \mathrm{~m}$ elevation and a period time of 10 seconds. Figure 10 shows the base shear force on the monopile mudline location to demonstrate the effects of wave loads. 


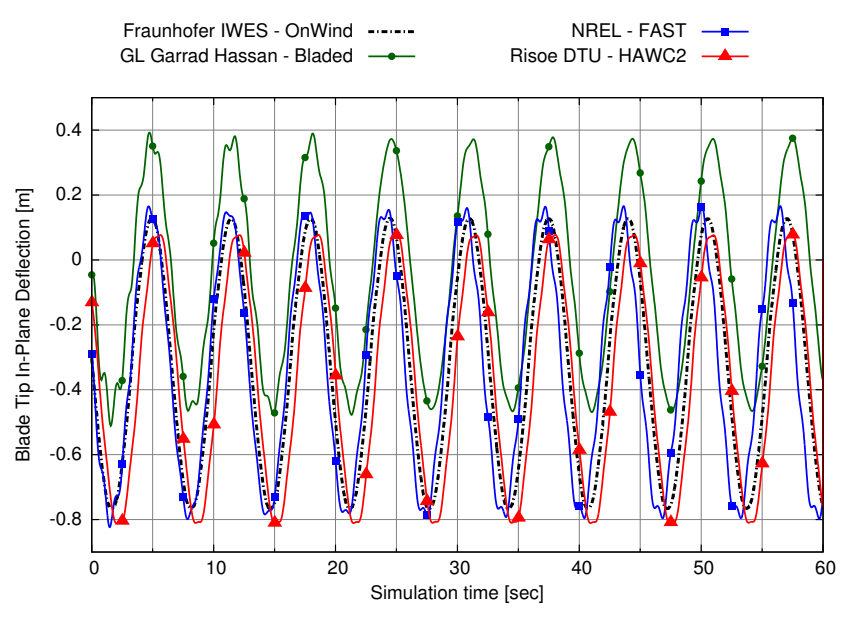

Figure 9: Time series of in-plane blade tip deflection in $[\mathrm{m}]$

In summary it can be said, that the results of the OnWind library compare well to the results of Phase I of the OC3 project. As the development of the OnWind library is still in progress, the small deviations that occured with respect to other simulation tools are subject to ongoing research.

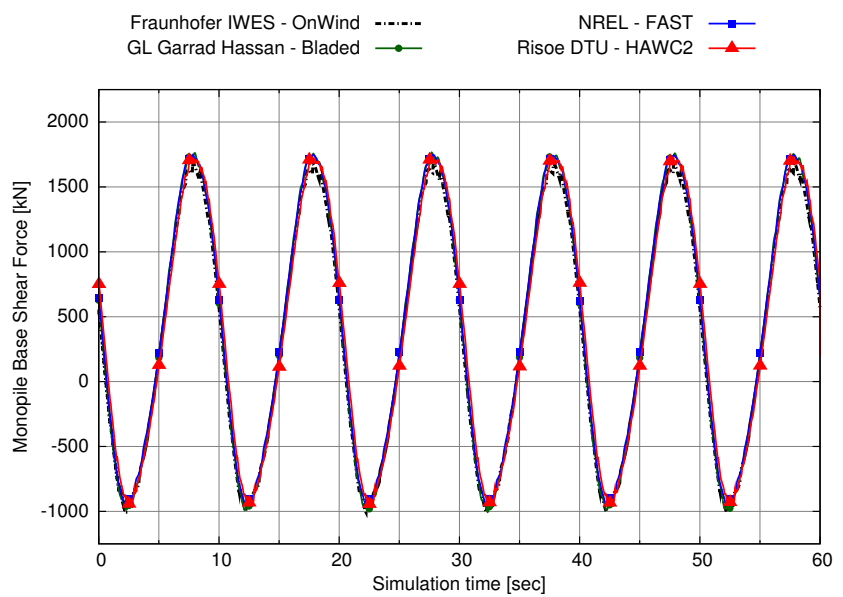

Figure 10: Time series of monopile base shear force $[\mathrm{kN}]$ in wind direction

\section{Conclusion}

It is shown that the Modelica Language is a good choice to develop a library for offshore windturbines. Especially the hydro-aero-servo-elastic coupling of the different components of a wind turbine is easy to implement. With respect to the short development time very good results compared to other established tools on the market are achieved.

The ongoing development of the OnWind library at Fraunhofer IWES concentrates on implementation of further substructure designs like tripod, jacket and floating structures in order to complete the comparison with the OC3 project. For these advanced structures the Timoshenko beam theory needs to be implemented. Additionally the integration of structural components as mode shapes is planned.

Furthermore investigations on further enhancements of the aerodynamic model like the dynamic stall and the wake model are in progress.

\section{References}

[1] G.B. Airy. On tides and waves. In Encyclopaedia Metropolitana, 1845.

[2] American Petroleum Institute (API), Washington DC, USA. RP 2A-LRFD: Recommended Practice for Planning, Designing and Constructing Fixed Offshore Plattforms - Load and Resistance Factor Design, 1993.

[3] A. Betz. Das Maximum der theoretisch möglichen Ausnötzung des Windes durch Windmotoren. Zeitschrift für das gesamte Turbinewesen, 26:307-309, 1920.

[4] R.E. Froude. On the part played in propulsion by differences of fluid pressure. Transactions of the Institution of Naval Architects, 30:390-405, 1889.

[5] H. Glauert. A general theory of the autogyro. ARCR R\&M, 1111, 1926.

[6] H. Glauert and L. Division. Airplane Propellers, Aerodynamic Theory, volume 4. Durand WF, Berlin, 1935.

[7] IEC. Wind turbines - Part 3: Design requirements for offshore wind turbines. IEC 61400-3, 1.0 edition, 2009.

[8] J. Jonkman. TurbSim User's Guide Version 1.5. National Renewable Energy Laboratory (NREL), Golden, Colorado, USA, 2009.

[9] J. Jonkman, S. Butterfield, W. Musial, and G. Scott. Definition of a 5-MW reference wind turbine for offshore system development. Technical report, National Renewable Energy Laboratory (NREL), Golden, Colorado, USA, 2009.

[10] J. Jonkman and W. Musial. IEA wind task 23 subtask 2: The offshore code comparison collaboration (OC3). Technical report, National 
Renewable Energy Laboratory (NREL), Golden, Colorado, USA, 2010.

[11] J.C. Kaimal, J.C. Wyngaard, Y. Izumi, and O.R. Coté. Spectral characteristics of surface-layer turbulence. Quarterly Journal of the Royal Meteorological Society, 98(417):563-598, 1972.

[12] T. von Kármán. Progress in the statistical theory of turbulence. In Proceedings of the $\mathrm{Na}$ tional Academy of Sciences of the United States of America, volume 34, pages 530-539, August 1948.

[13] J.R. Morison, M.P. O’Brien, J.W. Johnson, and S.A. Schaaf. The force exerted by surface waves on piles. Petroleum Transactions,AIME, 189:149-154, 1950.

[14] M. Otter. Modeling, Simulation and Control with Modelica 3.0 and Dymola 7. Technical report, Deutsches Zentrum fuer Luft- und Raumfahrt e.V. DLR - Institut fuer Robotik und Mechatronik, Wessling, Germany, 2009.

[15] M. Otter, M. Malmheden, H. Elmquist, S.E. Mattsson, and C. Johnsson. New formalism for modeling of reactive and hybrid systems. In Proceedings of the 7th Modelica'2009 Conference, Como, Italy, 2009. The Modelica Association.

[16] L. Quesnel, F. Vorpahl, and M. Strobel. Hydrodynamics meet wind turbines: specification and development of a simulation tool for floating wind turbines with modelica. In Proceedings of the 20th International Offshore and Polar Engineering Conference. Fraunhofer Institute for Wind Energy and Energy Systems Technology (IWES), 2010.

[17] W.J. Rankine. On the mechanical principles of the action of propellers. Transactions of the Institution of Naval Architects, 6:13-30, 1865. 